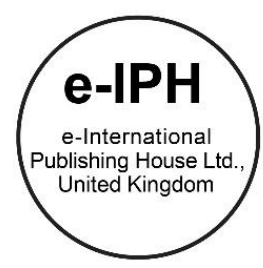

\title{
Performance Comparison of Basic Idea Sketches for Product Development between Manual Sketching and Computer Aided Design
}

\author{
Pracha Pijukkana1', Yanin Rugwongwan² \\ ${ }^{1}$ Arch D. Student, ${ }^{2}$ Asst. Prof., Ph.D., \\ Faculty of Architecture, \\ King Mongkut's Institute of Technology Ladkrabang (KMITL), Bangkok, Thailand. \\ ton pracha@hotmail.co.th \\ Tel: +66814037546
}

\begin{abstract}
This research is a qualitative study on basic idea sketches between Manual Sketching and Computer Aided Design Modeling (CAD). The result of this research will be to improve or to lead to design idea transferring process; that presents the product sketch, which is more advantage in respond to the designers' mindset, and the result will be recommended as a guideline for instruction industrial design which will be suitable for all students with different aptitudes in the design processes.
\end{abstract}

Keywords: Performance, Idea Sketch, Manual Sketching, Computer Aided Design.

eISSN: 2398-4287@ 2017. The Authors. Published for AMER ABRA by e-International Publishing House, Ltd., UK. This is an open access article under the CC BYNCND license (http://creativecommons.org/licenses/by-nc-nd/4.0/). Peer-review under responsibility of AMER (Association of Malaysian Environment-Behaviour Researchers), ABRA (Association of Behavioural Researchers on Asians) and cE-Bs (Centre for Environment-Behaviour Studies), Faculty of Architecture, Planning \& Surveying, Universiti Teknologi MARA, Malaysia.

https://doi.org/10.21834/e-bpj.v2i6.955

\subsection{Introduction}

Industrial design is a process of creating and developing a conceptual design that concerned with the outer appearance of the products by focusing on the Function, Value and Appearance of products including its format and size (Soodsang,2005). The purpose of industrial design is to develop the products that will maximize the benefits for users and manufactures. Product designs that incorporate the mentioned principles into the creating process will be appreciated among the consumers since these principle concepts are the fundamental element and the important factors that help to create an innovative, new style, and unique design. Also, the design that has systematic designing process can create an effective design with the hierarchical and systematic pattern. Based on the study of the Comparison of Concept Transferring Procedures of Basic Idea between Manual Sketching and Computer Aided Modeling, it shows the quantitative results of the number of basic idea sketches. Thus, this research aims to enhance the qualitative outcomes of the number of sketches which derive from these idea transferring processes; Manual Sketching and Computer Aided Design Modeling (CAD). These two product design processes have the same learning purposes which are to create ideas and support creativity by applying the concept of the interactions between the brain, hands, and shapes that appear on paper or the computer; however, their processes and tools are different.

\subsection{Literature Review}

Sahachaisaeree (2004) mentions the "Product Concept"; such as the basic definition of technology, principle of work and product format, that "Product Concept" is a brief definition of a design approach that can meet as many consumer needs as possible. Normally, design concept is roughly displayed in forms of hand sketches or 3D modelling with written explanation attached. And

eISSN: 2398-4287@ 2017. The Authors. Published for AMER ABRA by e-International Publishing House, Ltd., UK. This is an open access article under the CC BYNCND license (http://creativecommons.org/licenses/by-nc-nd/4.0/). Peer-review under responsibility of AMER (Association of Malaysian Environment-Behaviour Researchers), ABRA (Association of Behavioural Researchers on Asians) and cE-Bs (Centre for Environment-Behaviour Studies), Faculty of Architecture, Planning \& Surveying, Universiti Teknologi MARA, Malaysia.

https://doi.org/10.21834/e-bpj.v2i6.955 
whether how much the product can meet the needs of the consumers or how commercially successful it is, this mostly based on its hidden quality of product concept. Notably, even the professional designers also use the strategies and skills which derived from practicing the interaction between brain, hand and sketches which appears on papers (Laseau, 2001). This process is called Graphic thinking which is consistent with Design Development Spiral of Zeisel. The process of Graphic thinking begins with translating the images from the brain through hand and making the sketches onto the papers; the brain will respond to the basic ideas that appear on the papers through the eyes and will proceed to analyze and adjust by receiving signals from the brain through hands and translating it onto the papers. This graphic thinking process will repeat itself until created the design is satisfied. The characteristic of Design Development Spiral is: after the designers create the basic designs, they usually make changes to the original designs and develop the designs until they find the most satisfied one (Sahachaisaeree, 2004; Zeisel, 1981); this method is taught in product design. Currently, Manual Sketching and Computer Aided Design Modeling (CAD) become two of the most popular design idea transferring processes; which are often used to create the sketches of the products in the study of product design program.

Manual sketching is a product design process that applied 3D design onto 2D paper. Handmade design is one of design methods that are used to pass on the imagination of the designers onto the papers by using pencils or other tools depend on the designers' attitude. The handmade design has flexibility in designing and can create good imagination. Handmade design often uses to record spontaneous ideas and use to survey the optional designs. The key benefit of sketching in other areas such as product design and architectural design is to help designers to develop the ideas in creating different styles; such as new forms and shapes, more quickly and with more flexibility (Schon \& Wiggins, 1992).Drawing technique is an important skill for design, and sometimes sketch drawing is an important element that will be used to determine the direction of the design process and to lay the fundamental to see the beauty details or the ideas during the beginning of design process. Nowadays, the words sketching and drawing are wildly used to explain the activities of the designers and artists (Yusoff, 2007). The sketching technique beside using pencil or pen to draw on the papers is to use other tools in order to make the sketches look more real or to increase the understanding of product communications, these tools are such as markers, watercolor, colored pencils, color posters or other tools depending on the aptitude of the designers; however, the sketch elements remain the same.

Sketch design by computer modelling is the process that uses computer aided design to help to create the designs. CAD is a $3 D$ modelling, and the development of 3D modelling computer will help to create the designs that have forms and dimension that are more realistic because CAD is the art-based software. Computer Aided Design can create high-quality and realistic 3D designs, and it can stimulate accurate dimension. Therefore, using computer modelling is very helpful to create the designs because it can stimulate accurate angles. Especially in the final production process, in this process, every aspect of the design will be refined, all parts of the design will be developed, and the possibility to produce the product will be investigated. Thus, Computer-Aided Design can help create all designs, and it can help complete all the works, and make it possible to produce the initial ideas (Duku, 2014). ComputerAided Design is a tool that has been proven to have high-performance for designing support such as analysis or production. Also, it can be useful for designing choice or it can be used as the design guidelines for the new design (Woodbury, 2006).

From the comparison of concept transferring procedures of basic idea between handmade design and computer modelling, it shows that these two processes have the different beginning process and they require different tools. However, both of these two designing processes support the creativity in product design since they both require the thinking process which works on making the coordination between the brain, eyes and hands. Also, the differences between these two idea sketch processes affect teaching and learning industrial design. The research about the basic idea sketch transferring process found that manual sketching is an idea transferring process that helps to increase the imagination in idea sketch; also it can create more sketches and more variety of product designs than sketching via the computer aided modelling (Pijukkana \& Rugwongwan, 2017). In drawing the creative design, freehand sketching is often used to sketch the spontaneous ideas and it helps the designers to develop different design ideas such as shapes and forms in a fast and flexible manner (Schon \& Wiggins, 1992).On the other hand, the computer modeling process has the advantages in adjusting the images, colours and proportions. On the contrary, if the designers do not know how to work on the computer aided modeling properly, using it might limit their imagination (Yusoff, 2007). Computer modeling process might be appropriate for developing the ideas (Idea Development) and design drafts (Sketch Design). However, using the GPA of the students to determine their efficiency in transferring the idea sketch, the professor should investigate students' background and their past GPA standings before mixing students with different academic performance together (Ruengtam, 2014). The experimental results show that the group of students who have low GPA also have a lower than an average number of sketches. The groups of students, who have medium GPA, also have an average number of sketches. While the group of students with high GPA, also have the highest number of sketches. The group of students with high GPA is projected be the students who have effective initiation and have freedom of learning and creative thinking (Norshidah Nordin, 2016). Overall, the difference in academic achievement of the students does not affect the idea sketch transferring process. Nowadays, students have different thinking process, which might be due to their background; they can access the knowledge in the form of critical knowledge synthesis and self-exploration. Moreover, they can recognize the difficulty and complexity of the designs and the individual differences in term of learning style, design ability and communication skills (Adi, 2015).

\subsection{Methodology}

This research selects the sample groups from random samples, which are the non-probability sampling, who are the undergraduate students from the 4th year's industrial product design program from Rajamangala University of Technology Phra Nakhon. The sample group of 56 students will be divided base on their academic standing and their aptitude in sketch design process. One of the students 
will be chosen to make the sketch design using both handmade design and computer modeling process within the same time frame. The number of sketches/ time will be recorded, in each experiment, the time will be increased by 15 minutes, the experiment will be repeated until the time reach 120 minutes. After that the researchers will assess the quality of the sketches that can be used in the development of industrial products.

\section{Data Collection}

Then the researchers will synthesis the process of transferring the basic ideas to present the sketches of the undergraduate design students, to find the point that will be used as the indicator for the assessment, and to create tools that will be used to evaluate the learning and teaching industrial design. The data collecting methods will be divided into three steps as follows

Collecting the academic performance data (Transcript) of the 4th year undergraduate industrial design students and divided the students into groups by using Cluster Analysis to find the attitudes indication factors. Dividing the academic performance into two parts, the first part is the Grade Point Average (GPA) which can be divided the student according to their GPA into three groups; the group of students that have high GPA in industrial product design 1-3 class, sketching class, and painting techniques class and other classes that involve hand sketching will be classified as the classes that have an aptitude in handmade drafting. However, if the students have high GPA in industrial product design, 4-5 classes, computer for design and production classes and other classes that involve using computers to create the designs will be classified into the group that has an aptitude in using the computer for design process.

Testing the concept of the idea sketching by choosing the required group from the Non-probability Sampling. The students from the selected groups will be asked to create the designs by using both the handmade design process and computer modelling process. The given designs for handmade process and computer modelling process will be different: however, it will have similar degree of difficulty. This is because if the students have the experience of making the same design over and over again, they will tend to develop the idea development instead of creating idea sketch. The winning design will be chosen from the products that can transfer the idea sketch which can also create many imaginations. In this research, the researchers ask the group that uses handmade design process to make a design for toaster and ask the computer modelling process group to create a design for rice cooker. These two products design has the similar level of difficulty and complexity. The designs will be sketched by hand on 100 pounds papers or by computer using the $\mathrm{A} 2(420 \times 594 \mathrm{~mm})$ size paper.

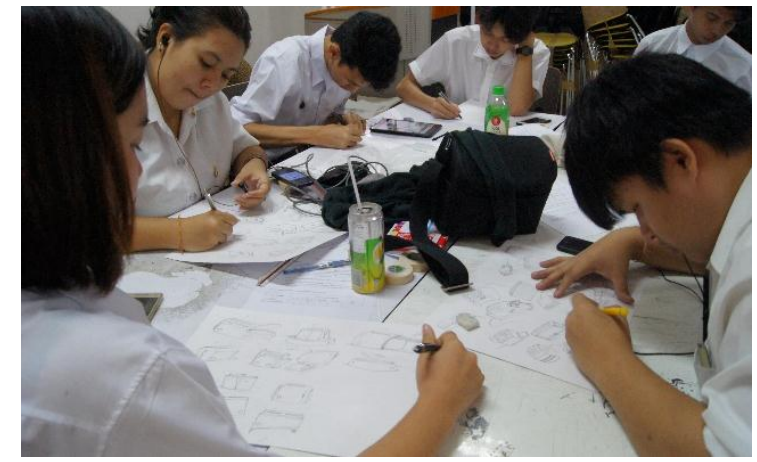

(a)

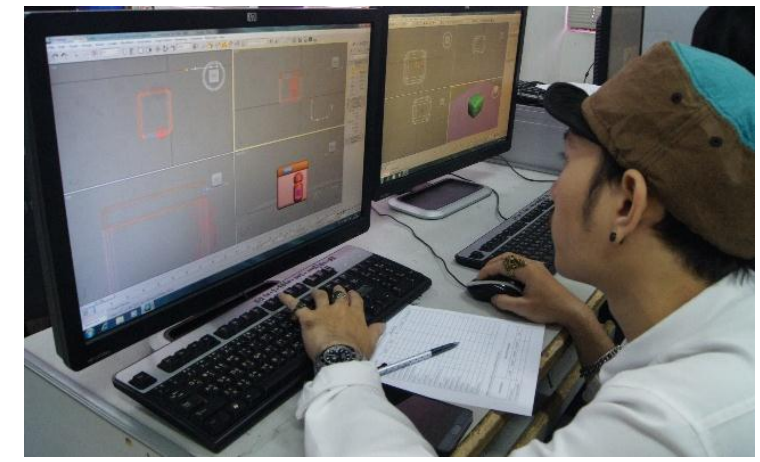

(b)

Fig. 1. (a) Manual sketch process; (b) Computer aided design process.

Quality assessment will be conducted after the students create their basic idea sketch of the product (Idea sketch). After finishing all processes, these sketches will be sent to 30 professors from different universities, who involved in teaching product design, to evaluate the quality of sketches from these basic idea sketching processes that can be used in the development of industrial products which will lead to the next step of the design idea development.
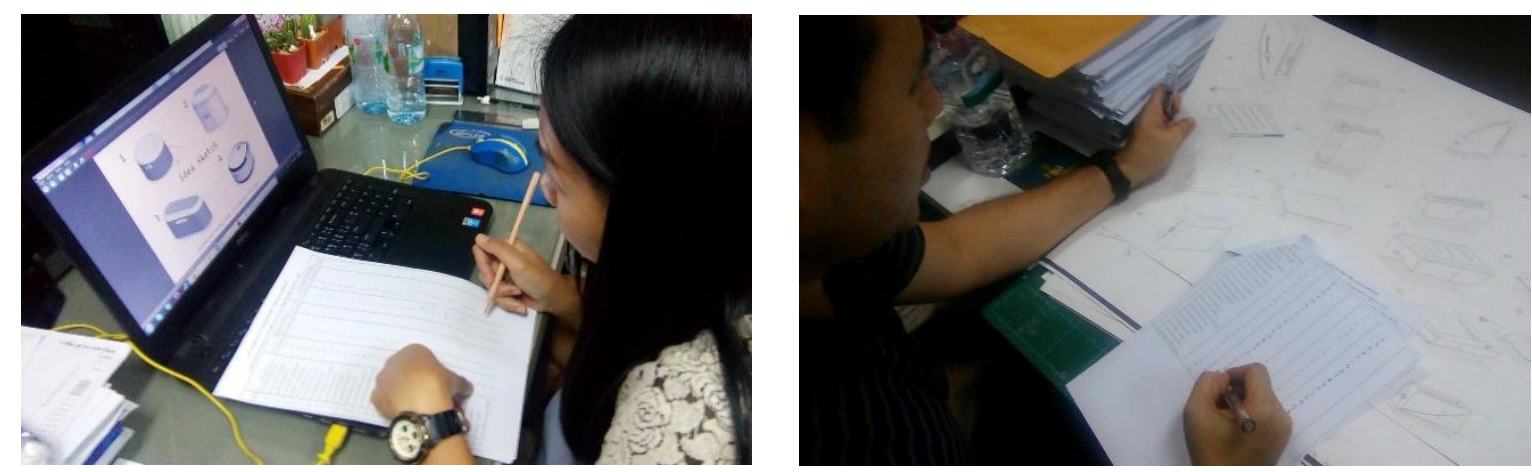

Fig. 2: Quality assessment of idea sketch by professors 


\subsection{Discussion and Analysis}

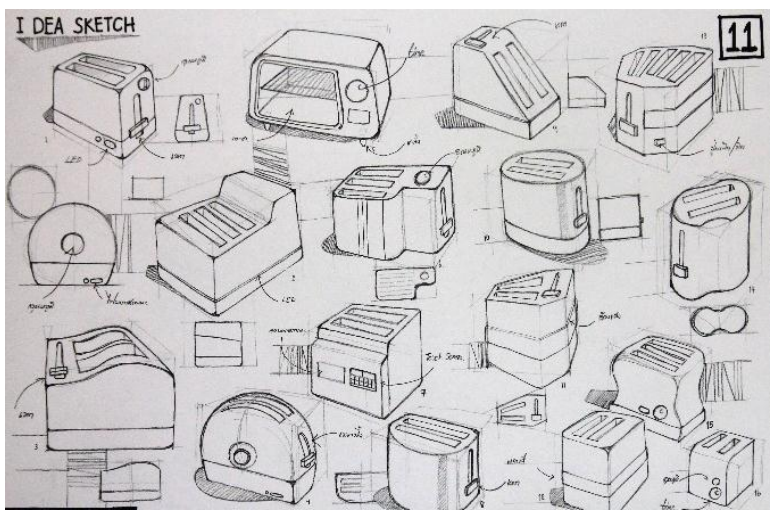

(a)
IDEA SKETCH Nmusers2

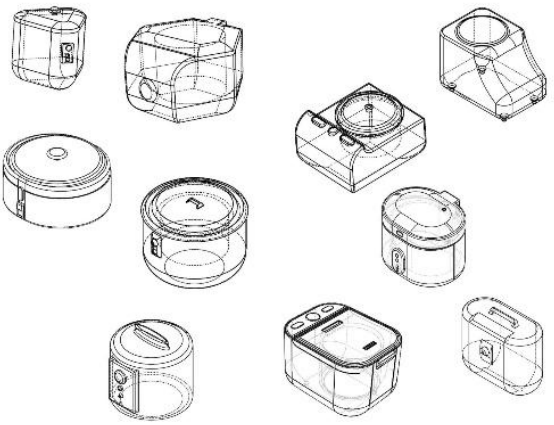

(b)

Fig. 3. (a) Idea sketch by Manual Sketching process; (b) Idea sketch by Computer Aided Design process.

From testing idea sketch by using manual sketch and computer aided design of 56 students of the 4th year industrial design program. These students are grouped according to their aptitude. It was found that 37 students are put into a group of students with an aptitude in manual sketch process and 19 students are put into group of students with an aptitude in computer aided design modeling process. Each round, the students had 15 minutes to create the designs, and the designing process will continue until the time reach 120 minutes. The analysis results found that the students can create the sketches at the average of 16.78 sketches per 15 minutes by using manual sketch process which is more than the computer modeling process that can only create sketches at the average of 6.63 sketches per each 15 minutes. Also, there are sketches that can be further developed by manual sketch process at the average of 6.34 sketches per round while the computer aided design modeling process can only create these sketches at the average of 2.37 .

From examining the difference between the average number of the basic idea sketches; to develop the product design according to the student's aptitude, between manual sketch process and computer aided design modelling process (CAD), each process is not independent to each other. The analysis result yielded that the aptitude test of these students/ the process and the overview that has an impact on manual sketch process and computer aided design modelling process(CAD) have the statistically significant difference at the 0.05 (see Table.1)

Table 1: Comparing the performance of the basic idea sketch for product development according to student's aptitude between manual sketch process and computer aid design process

\begin{tabular}{|c|c|c|c|c|c|c|c|c|c|c|c|c|}
\hline \multirow{3}{*}{$\begin{array}{l}\text { Student's aptitude/ } \\
\text { sketching process }\end{array}$} & \multicolumn{5}{|c|}{ Basic idea sketch by Manual Sketching } & \multicolumn{5}{|c|}{ Basic idea sketch by Computer Aided Design } & \multirow{2}{*}{\multicolumn{2}{|c|}{$\begin{array}{l}\text { Paired Samples Test } \\
\text { Number of sketches } \\
\text { that can be further } \\
\text { developed }\end{array}$}} \\
\hline & \multicolumn{2}{|c|}{$\begin{array}{l}\text { Number of } \\
\text { sketches }\end{array}$} & \multicolumn{2}{|c|}{$\begin{array}{l}\text { Number of } \\
\text { sketches that } \\
\text { can be further } \\
\text { developed }\end{array}$} & \multirow[t]{2}{*}{$\%$} & \multicolumn{2}{|c|}{$\begin{array}{l}\text { Number of } \\
\text { sketches }\end{array}$} & \multicolumn{2}{|c|}{$\begin{array}{l}\text { Number of } \\
\text { sketches that } \\
\text { can be further } \\
\text { developed }\end{array}$} & \multirow[t]{2}{*}{$\%$} & & \\
\hline & $\bar{X}$ & S.D. & $\bar{X}$ & S.D. & & $\bar{X}$ & S.D. & $\bar{X}$ & S.D. & & $t$ & $P$ \\
\hline $\begin{array}{l}\text { Aptitude in Manual } \\
\text { Sketching }\end{array}$ & 16.77 & 4.88 & 6.41 & 2.44 & 38.08 & 5.95 & 3.61 & 1.82 & 0.91 & 33.05 & 11.87 & 0.00 \\
\hline $\begin{array}{l}\text { Aptitude in Computer } \\
\text { Aided Design }\end{array}$ & 16.84 & 6.85 & 6.22 & 3.44 & 34.23 & 7.95 & 4.54 & 3.46 & 2.30 & 41.92 & 5.06 & 0.00 \\
\hline Total & 16.78 & 4.87 & 6.34 & 2.79 & 36.78 & 6.63 & 4.03 & 2.37 & 1.70 & 36.06 & 11.90 & 0.00 \\
\hline
\end{tabular}

This table shows the analysis of variance tests indicate the differentiating factors between student's GPA that affect the number of sketches and the number of sketches that can be further developed during the idea sketch transferring process. By using students' GPA data, it can separate students into three groups. First is a group of students who have low GPA and have the lowest average number of sketches, there are 15 students in this group with the average of 9.57 sketches and has 2.58 sketches that can be further developed. Next is a group of students who have the average GPA and have the average number of sketches, there are 22 students in this group with the average number of sketches equals 11.55 sketches and has 3.94 sketches that can be further developed. Last is a group of students with high GPA and also have the highest average number of sketches, there are 19 students in this group which have the average number of sketch equals 13.58 sketches and has 6.25 sketches that can be further developed. The overview of this test indicates that the GPA of the students has an effect on the basic idea transferring process $F(2,109)=16.55, p=.00$, the Manual Sketching process $F(2,109)=40.72, p=.00$ and the Computer Aided Design modeling process $F(2,109)=7.10, p=.00$ has statistical significant different at 0.05 , and it can be concluded that there is at least one group of students, with different GPA, have an effect on the basic idea sketch transferring process (see Table. 2), thus it is necessary to make the comparison between each group of students after doing analysis of variance. 
Table 2: Comparing the basic idea sketch for product development from students' GPA

\begin{tabular}{|c|c|c|c|c|c|c|c|c|c|c|c|c|c|c|}
\hline \multirow{3}{*}{$\begin{array}{l}\text { Sketching process/ } \\
\text { Student's GPA }\end{array}$} & \multicolumn{4}{|c|}{ Low GPA } & \multicolumn{4}{|c|}{ Average GPA } & \multicolumn{4}{|c|}{ High GPA } & \multicolumn{2}{|c|}{ ANOVA } \\
\hline & \multicolumn{2}{|c|}{$\begin{array}{l}\text { Number of } \\
\text { sketches }\end{array}$} & \multicolumn{2}{|c|}{$\begin{array}{l}\text { Number of } \\
\text { sketches that } \\
\text { can be further } \\
\text { developed }\end{array}$} & \multicolumn{2}{|c|}{$\begin{array}{l}\text { Number of } \\
\text { sketches }\end{array}$} & \multicolumn{2}{|c|}{$\begin{array}{l}\text { Number of } \\
\text { sketches that } \\
\text { can be further } \\
\text { developed }\end{array}$} & \multicolumn{2}{|c|}{$\begin{array}{l}\text { Number of } \\
\text { sketches }\end{array}$} & \multicolumn{2}{|c|}{$\begin{array}{l}\text { Number of } \\
\text { sketches that } \\
\text { can be further } \\
\text { developed }\end{array}$} & \multirow[t]{2}{*}{$\mathrm{F}$} & \multirow[t]{2}{*}{$P$} \\
\hline & $\bar{X}$ & S.D. & $\bar{X}$ & S.D. & $\bar{X}$ & S.D. & $\bar{X}$ & S.D. & $\bar{X}$ & S.D. & $\bar{X}$ & S.D. & & \\
\hline $\begin{array}{l}\text { Manual Sketching } \\
\text { process }\end{array}$ & 14.0 & 5.52 & 3.68 & 1.77 & 16.05 & 3.59 & 5.76 & 1.61 & 19.84 & 4.09 & 9.11 & 1.98 & 40.72 & 0.00 \\
\hline $\begin{array}{l}\text { Computer Aided Design } \\
\text { Modeling process }\end{array}$ & 5.13 & 2.26 & 1.47 & 0.52 & 7.05 & 4.29 & 2.11 & 1.14 & 7.32 & 4.63 & 3.39 & 2.29 & 7.10 & 0.00 \\
\hline Total & 9.57 & 6.13 & 2.58 & 1.71 & 11.55 & 6.00 & 3.94 & 2.31 & 13.58 & 7.67 & 6.25 & 2.29 & 16.55 & 0.00 \\
\hline
\end{tabular}

Based on the variance analysis, the variation of the difference factors between student's GPA, which has an effect on the number of sketches that can be further developed in the basic idea transferring process, have statistically significant differences. Thus, it is necessary to make a paired comparison which will display the statistical data for the multiple comparisons test. By doing the LSD test in Manual sketching process, it shows that the group of students with low GPA has $M=3.68, S D=1.77$, the group of students with average GPA has $M=5.76, S D=1.61$ and the group of students with high GPA has $M=9.11, S D=1.98$. Also, the pair comparison test between the group with average GPA and high GPA shows that these two groups have an impact on the basic idea sketch transferring with the statistically significant differences 0.05 . On the other hand, the LSD test in the Computer aided Design process yields that the group of students with low GPA has $M=1.47, S D=0.52$, the group of students with average $G P A$ has $M=2.11, S D=$ 1.14 and the group of students with high GPA has $M=3.39, S D=2.29$. Also, the pair comparison test between the group with average GPA and high GPA shows that these two groups have an impact on the basic idea sketch transferring with the statistically significant differences 0.05 ; while the pair comparison test between the group with low GPA and average GPA does not show any difference.

\section{Conclusion and Recommendations}

From the performance comparison of the basic idea sketch for product development between manual sketch process and computer aided design modeling process (CAD) shows that students that have an aptitude in Manual Sketching can create more sketches and can use these sketches to make a further developing than the students that have an aptitude for Computer Aided Design. However, if we compare the proportion between the number of sketches and the number of sketches that can be further developed, we will find that the number of sketches that can be further developed between these two processes has slightly different percentage. Although the Computer Aided Design Modeling Process (CAD) yield less number of sketches, its proportion is close to the number of sketches than the Manual Sketching Process. Moreover, the creating of basic design idea based on the need of the users and product target details will give the result such as a set of product concepts developed which the product development team will select from this set of concepts. This demonstrates the relationship between conceptualization process and other product development activities process. In general, effective design teams often create hundreds of design ideas, and in many of these designs, only 5-20 sketches will be seriously considered in the activity phase of choosing the idea (Sahachaisaeree, 2004).

In addition, student's grade point average (GPA) is another important factor in the number of sketches. It can be seen that the GPA of the students will affect the basic idea transferring process respectively. The number of drafts can be reduced. The conceptual idea is close to the middle and high levels. Although the group of students with low GPA can create almost the same number of sketches as the group of students that have average and high GPA, these are not many sketches that can be further developed when comparing to the group of students higher GPA.

The recommendation from this research is that there are factors other than student's aptitude and GPA that have an effect on basic idea transferring process. The researcher thinks that environmental is another factor that may affect the basic idea transferring process. These environmental factors are such as sitting patterns, such as sitting in a group or sitting alone, may affect the idea exchange which can be used for improving or developing the concept idea design (Idea Development) and sketch design as well.

\section{Acknowledgements}

The author would like to thank Assoc. Prof. Dr.NopadonSahachaisaeree and Asst. Prof. Dr.YaninRugwongwan, Faculty of Architecture, King Mongkut's Institute of Technology Ladkrabang, Thailand, for their kind suggestions, guidance, and support to the researcher. I also would like to thank Faculty of Architecture and Design, Rajamangala University of Technology Phra Nakhon, Thailand, for a scholarship to pursue my $\mathrm{PhD}$ course work and dissertation.

\section{References}

Adi, F. e. (2015). Conceptualisation as Key Factor in Seizing Design Project in Studio Learning Environment. Journal of ASIAN Behavioral Studies, 5(20), 13-23 
Laseau, P. (2001). Graphic thinking for architects and designers. London: Vanostand.

Nordin, N. e. (2016). Assessing Readiness for Self-Directed Learning among College Students in the Provision of Higher Learning Institution. 7thAcE-Bs2016Taipei (pp. 91-101). Taiwan: AMER ABRA.

Pijukkana P, Y. R. (2017). Comparison of Concept Transferring Procedures of Basic Idea between Handmade Design and Computer Modeling. AicQoL2017Bangkok 5th AMER International Conference on Quality of Life, (pp. 121-125). Bangkok: AMER ABRA.

Ruengtam, P. (2014). Cooperative/Collaborative Learning in an Interior Architectural Program. Journal of ASIAN Behavioural Studies, 4(17), 31-40.

Sahachaisaeree, N. (2004). Sustainable paradigm in interior design. Bangkok: Kasembundit University.

Schon, D. A., \& Wiggins, G. (1992). Kinds of seeing and their functions in designing. Design Studies, 13(2), 135-156.

Soodsang, N. (2005). Industrial Design Research. Bangkok: Odeon Store.

Woodbury, R. F. (2006). Whither design space" artificial intelligence. Analysis and Manufacture, 20(2), 63-82. doi:10.1017/S0890060406060057

Yusoff, S. B. (2007). Automotive Sketching Techniques from Education and Professional Practice. Birmingham City: Birmingham City University.

Zeisel, J. (1981). Inquiry by design: tools for environment-behavior research. Cambridge: Cambridge University. 